\title{
Rural Islandness as a Lens for (Rural) HCI
}

\author{
SARAH ROBINSON, NICOLA J. BIDWELL, ROBERTO CIBIN, CONOR LINEHAN, \\ LAURA MAYE, and JOHN MCCARTHY, University College Cork \\ NADIA PANTIDI, Victoria University of Wellington \\ MAURIZIO TELI, Aalborg University
}

\begin{abstract}
This article contributes to research that aims to better understand and describe the rural context for rural computing. We argue that the particularities of rurality are heightened by the experience of 'islandness'. We report on our experiences of engaging on one small island as islanders established community radio using a novel platform. Data comes from 12 semi-structured interviews with community members and ethnographic field notes assembled through eight researcher visits to the island. Transcripts and notes were analysed using thematic analysis. We discuss how rural islandness as a socio-cultural lens influenced technology appropriation and factors to support participation. We explore the elements of rural islandness that can be used as an analytic tool for rural $\mathrm{HCI}$ and $\mathrm{HCI}$ more broadly, through three main contributions of rural islandness that we believe have not yet been sufficiently explored in HCI. These are (1) separateness, (2) pushing things ahead, and (3) publics and rural pluralities.
\end{abstract}

\section{CCS Concepts: • Human-centered computing $\rightarrow$ Empirical studies in HCI;}

Additional Key Words and Phrases: Rural HCI, islandness, community radio, community engagemen, publics, rural studies, ethnography, thematic analysis

\section{ACM Reference format:}

Sarah Robinson, Nicola J. Bidwell, Roberto Cibin, Conor Linehan, Laura Maye, John McCarthy, Nadia Pantidi, and Maurizio Teli. 2021. Rural Islandness as a Lens for (Rural) HCI. ACM Trans. Comput.-Hum. Interact. 28, 3, Article 20 (May 2021), 32 pages.

https://doi.org/10.1145/3443704

\section{INTRODUCTION}

There is growing recognition that digital technology is designed primarily to fit within urban infrastructures and to support urban ways of living [4, 29, 31-33, 37]. Often, upon recognition that digital goods and services do not work as intended in rural contexts, those rural contexts are

Authors' addresses: S. Robinson, N. J. Bidwell, R. Cibin, C. Linehan, L. Maye, J. McCarthy, School of Applied Psychology, UCC, Cork. Ireland T23 TK30; emails: \{sarahrobinsonis, nic.bidwell\}@gmail.com, mr.r.cibin@gmail.com, \{conor.linehan, laura.maye, john.mccarthy\}@ucc.ie; N. Pantidi, Computational Media Innovation Centre, Faculty of Engineering Victoria University of Wellington, Level 3, 40 Taranaki Street Wellington 6011, New Zealand; email: nadia.pantidi@vuw.ac.nz; M. Teli, Department of Planning, Aalborg University, Rendsburggade 14, 9000 Aalborg, Denmark; email: maurizio@aau.dk. Authors's current address: S. Robinson, IT Carlow, Wexford Campus, Wexford, Y35 KA07; N. J. Bidwell, International University of Management, Namibia; R. Cibin, Institute of Sociology of the Czech Academy of Sciences, Jilská 1, Praha 1, 110 00, Czech Republic.

Permission to make digital or hard copies of all or part of this work for personal or classroom use is granted without fee provided that copies are not made or distributed for profit or commercial advantage and that copies bear this notice and the full citation on the first page. Copyrights for components of this work owned by others than the author(s) must be honored. Abstracting with credit is permitted. To copy otherwise, or republish, to post on servers or to redistribute to lists, requires prior specific permission and/or a fee. Request permissions from permissions@acm.org.

(C) 2021 Copyright held by the owner/author(s). Publication rights licensed to ACM.

1073-0516/2021/05-ART20 \$15.00

https://doi.org/10.1145/3443704 
construed through a deficit model [30] In reality, those contexts contain geographical, social and cultural features that have simply not been 'designed for', or rarely considered as part of design processes [32]. This article contributes to a recent conversation in HCI that aims to better understand and describe rural contexts, in order to support people in designing digital goods and services that are respectful of, and valuable to, people living and working in them. We aim to contribute to rural computing in $\mathrm{HCI}$, through introducing a particular form of rurality called rural islandness. We draw on Hardy, Wyche and Veinot's [29] descriptive, socio-cultural and symbolic definitions of rurality, to illustrate how rural islandess involves particular features of each definition. Descriptive features of rural islandness include low population size and density, unique infrastructure dilemmas, particular social networks and culture and values and particular forms of distance and isolation that being surrounded by the sea creates. From a socio-cultural perspective, we suggest that islandness indicates not only, 'the differences in behaviour, attitudes and values that differentiate rural people from urban people', [29:8] but also the differences in behaviour, attitudes and values between rural island dwellers, as the boundedness of the island creates a heightened awareness and performance of identities that are carefully managed and lead to particular ways of relating $[11,23]$. Lastly, we suggest that rural islandness as 'a discursive category from which people form attachments' [29:8] can be heightened, as in the case of the rural islands in Ireland, which form an important part of the Irish collective consciousness as symbols of an ideal Irish identity, based on rurality [21].

In general, we argue that the particularities of rurality are heightened, and marked out as distinctive, by the experiential quality of being surrounded by the sea. In short, rural islandness draws attention to the ways in which islanders, 'assemble[s] together an island by way of making use of whatever is at hand, solving ongoing concerns as they present themselves' [54:225], and the ways in which they collaborate and socially interact are particular to place-making of a rural island. We are interested in exploring what HCI can learn through the lens of rural islandness that can be used in future design projects that aim to be valuable to islanders, as well as other rural contexts. We also seek to understand how engagement with islandness inflects understanding of rurality, rural $\mathrm{HCI}$, and $\mathrm{HCI}$ more generally.

In Section 2, we introduce the concepts of rurality, islandness and rural islands. We draw on literature from Cultural and Rural Geography, Island Studies and Science and Technology Studies (STS) that reveals multiple threads of rurality. We highlight what rural islandness has to offer to this agenda; in particular, how it makes us question traditional HCI methods, approaches and motivations and introduces new ways of considering concepts such as publics as we consider rural pluralities. We also illustrate how HCI research has already explored rural islands as a rich site of investigation into how islander values can be aligned or ignored by technology. We seek to contribute through bringing together this diverse literature for the first-time, examining commonalities that can support rural computing whilst engaging on rural islands and identifying challenges for traditional HCI methods that might be useful for rural computing more broadly.

We seek to build on this limited but rich literature related to rural island contexts in HCI, through identifying specific characteristics of small rural islands that influence how inhabitants engage with research and design and, in turn, how technology projects align (or not) with their needs and aspirations. Some of these characteristics might be shared with other rural and non-rural contexts. However, we argue that they are amplified on small rural islands, which has led us to make rural islandness focal in this article and has encouraged us to think about its potential value in our HCI research in general. Thus, we propose that, as well as increasing HCI's sensitivities to islands, the lens of rural islandness can be an analytic tool to deploy in other geographic areas for HCI.

We will use that construct to critically position HCI studies of island life and rural islandness as a starting point for our analysis of early encounters with people on a small rural island, in 
which we explored the potential value of introducing community radio for islanders. To do this, we present a thematic analysis of semi-structured interviews and ethnographic notes as part of a project to establish a micro-community radio with people on one rural island. Here, we present an analysis of the experiences and values of the islanders, which results in an empirical clarification of rural islandness as it pertains to the particularities of lived experience on that island. Then, we describe the introduction of community radio technology, and attempts to deploy it on the same rural island, and what further that reveals about lived experience and islandness and the richness of the concept and experience of islandness in those practices. Finally, in the Discussion (Section 5), we will open out from a tight focus on islandness on one small rural island to examine how the richness of that experiential quality of island living can connect with rural $\mathrm{HCI}$ and with $\mathrm{HCI}$ in general. ${ }^{1}$

\section{RELATED WORK}

In this section, we define the specific qualities of islandness by describing some of the ways in which islandness differs from and coincides with rurality. As a specific and distinctive form of rurality, presenting rural islandness here is intended both to name a particular geographical category and an experiential quality to contribute to the rural HCI agenda and to value heterogeneity of experience. As a focus on the rural in HCI provides novel insights on privacy, values, and space/place, so a focus on rural islands and islandness provides novel insights on multiple ruralities, ways of relating and identity processes relevant for rural computing. In this section, we will present our thinking on the distinctiveness of islandness as a specific form of rural life.

\subsection{Rurality, Rural Islands and Rural Islandness}

Rurality as a concept has been viewed through multiple lenses in geography and HCI. While HCI has traditionally engaged with rural communities and places through ICT4D and HCI4D, this emphasis has largely been on computing's role in development, rather than centring rurality itself as an organizing principle [29]. There are renewed efforts within HCI and CSCW to centre rurality through what Hardy and colleagues refer to as Rural Computing, defined as 'understanding, designing and building computing technologies that are particular to the needs, aspirations and practices of rural communities around the world'. [32:38] This new area of HCI emphasises the need to design 'from and with' the rural [32]. Hardy et al. [29] point to the varieties of ways in which HCI research engages with rural communities, the lack of definition of rurality in much of that research, and the tendency to emphasise physical characteristics such as distance, lack of infrastructure, and geographic isolation as distinctive characteristics of rural places. They found less on the imaginative and practiced elements of rurality, which Hardy and colleagues refer to as the 'symbolic' and 'socio-cultural'. By symbolic they mean a discursive category that is understood abstractly at scale beyond the local rural place. Socio-cultural definitions of rurality, on the other hand, '[highlight] the extent to which people's socio-cultural characteristics vary with the type of environment in which they live', [29:5] that can influence technology design, appropriation or resistance.

Geographical approaches to rurality are also varied, with approaches ranging from descriptive, to discursive, to the material $[26,27,60]$. Woods [60] emphasizes the interdependence between how

\footnotetext{
${ }^{1}$ The research reported here is part of an EU funded project (Grassroots Wavelenghts) to deploy an FM radio peer-to-peer platform (RootIO) in rural and peripheral contexts in Europe, to support rural communities to have a platform for citizen engagement, to deliberate community issues, support the free-flow of information into and out of the area and enable media pluralism. RootIO was initially developed and deployed in rural Uganda as a simple low-cost technology that did not require a studio nor much of the hardware traditionally associated with radio.
} 
meanings/representations attributed to the rural shape the social and economic structure of rural localities and material realities of those that live there. He [60] also suggests that while urban areas are customarily emphasized as dynamic, rural places are also fluid, characterized by a diversity of lived experiences shaped, negotiated and contested by the various rural representations, and the wide range of micro-communities that inhabit rural places. Yet this diversity and dynamism of rural experiences if often forgotten in binary distinctions of rural and urban [4].

The plurality of rural representations emphasises, for example, the rural as the site of productivity, as wilderness [4], as tourist commodity [60], as idyll and quaint [26], as backward and underdeveloped and in need of modernization [42, 43], and as site of innovation [58]. These diverse representations also correspond with multiple co-existing rural communities. For example, the same geographic territory may contain farming communities, migrants, summer homeowners and tourists escaping [urban] lives [60]. Rural communities then can be 'affluent, deprived, agricultural, industrial, stable, mobile and so on'. [47:4] In Ireland, geography research also suggests that rural men are often positioned as staying 'behind', positioned as failing in masculinity if they remain $[42,43]$. Such representations of the rural as 'backward' might be internalized or rejected by rural dwellers. As Halfacree [27] suggests some representations of the rural are in tension with the lived and material realities of inhabitants. For example, farmers may not appreciate rural representations as sites of consumption for tourists, whilst conservationists may not enjoy rural representations as a site of production. As a result, ruralities are complex, plural and contested. In line with recent calls to engage with rural pluralities [29, 33], HCI responses to lived experiences in rural communities should be understood in dialogue with plural ruralities. Against this background, Hardy and colleagues [32] suggest that to design 'from the rural' and to conduct HCI research in rural places, we need to understand how rural dwellers consider rurality in their lives.

Our contribution is to focus on rural islandness as a specific form of rurality in which elements of descriptive, socio-cultural and symbolic definitions described by Hardy, Wyche and Veinot [29] come to the fore in distinct ways. To our knowledge, the relationship between islandness and rurality have not been explicitly explored, despite notable studies in rural island contexts [8-10, $13,17-20,22,44,45,50,51,57,58]$, and to our knowledge, the concepts have not yet been explicitly brought together. Islandness, just like rurality, is a contested term, emphasized differently across the island studies and geographic literature [1, 3, 23, 34, 54]. For example, Hay [34] finds divergent views about whether it should be considered metaphorically or as reality of place; or whether the isolation of the island defines it or the connectedness through the sea and lastly whether or not islander identity is tenacious or more fluid. There seems to be somewhat of a consensus though that what is distinct about islands in an era of globalisation is their unique and heightened sense of place [1,34]. We draw on two theories of islandness; the first by Gill[23] indicates that the boundedness of the island creates unique ways of relating and identity dynamics, and the second by Vannini and Taggart [54], suggests that islandness is defined by the practice of islanding, that is that islandness is the act of islanders 'assemble[ing] together an island by way of making use of whatever is at hand, solving ongoing concerns as they present themselves' [54:225]. We will now briefly explore how elements of ruralities and islandness interact to form what we consider to be rural islandness.

Firstly, the rural islands we focus on meet the descriptive characteristics of rurality as identified by Hardy, Veinot and Wyche [29]. Similarly, to other rural contexts, rural islands have low population density and size, but they are more acutely aware of population declines than other rural contexts, due to the threat of community extinction within a generation, if depopulation occurs $[11,57,58]$. As a result, rural islands constantly rely on in-migration to sustain them [11, 23]. Yet there are hierarchies about who has the right to islander identity and belonging [11, 23]. As a result, islands offer an interesting case study for understanding impacts of migration flows 
on rural cultures, and on understanding rural pluralities. While infrastructure is often different in rural contexts, rural island populations are particularly vulnerable to infrastructure break-downs and rely on each other for maintenance and repair [44, 45]. As Watts [57:16] states, 'the dependent infrastructures of contemporary living, forgotten and literally buried in urban places, are visible and embodied in the weather-reliant ferries, in the occasional electricity black-outs, in the 'not spots' of absent broadband and mobile phone signal', and as a result, rural islands are often conceived as 'isolated spaces at the edges of these [contemporary infrastructural] network[s]' [44:82], providing us rich insight into the importance of maintenance and repair for design in this type of context, where breakdown can be the norm rather than unusual $[44,45]$.

Distance and geographic isolation is also unique on rural islands, due to unique spatial practices that involve a dependency on ferries for access to the mainland, and vital social and medical services. This way of accessing the island creates mobilities and (im)mobilities when the weather, cost or breakdowns prevent travel. Rural islands' separation from the mainland is both a resource and a constraint, facilitating feelings and experiences of insulation (associated with protection, safety, distinct collective and individual identity and disconnection) and isolation (vulnerability, marginality, financial hardship and inescapability), and there is a constant tradeoff between the two [53].

From a socio-cultural perspective, just like Hardy et al. who suggest that, 'sociocultural characteristics vary with the type of environment in which they live', [29:4] we find that the descriptive characteristics of rural island contexts lead to particular ways of relating. For example, as a result of the geographic distance and isolation of rural islands, mutual-reliance when infrastructure breakdown, and ferry-dependencies lead to 'unrelenting collaboration' to survive [58:207]. As a result there is extreme care in maintaining social relations, even in the face of tensions [58]. As Watts finds on Orkney, 'You have to sit on your tension [and disagreements] because tomorrow you might need that person. [For example] He is the only plumber on the island, so you cannot fall out with him'. [58:204] Collaborations are formed with anyone or anything required to dwell in the rural island context, making Oracadians in Watt's [58] view akin to Haraway's 'oddkin', forming 'unexpected collaboration and combinations'. [28:4]

We also suggest that similarly to socio-cultural definitions of rurality, islandness indicates, 'the differences in behaviour, attitudes and values that differentiate rural people from urban people', [29:8] but also the differences in behaviour, attitudes and values between rural island dwellers, as the boundedness of the island creates a heightened awareness and performance of identities. Identity is usually constructed in relation to others and Burholt, Scharf and Walsh suggest that island dwellers have a 'mutual vested interest in (re)creating an identity through social interaction that symbolically homogenises the island population (islanders and migrants) as a traditional and socially cohesive community, retaining its distinctiveness from the mainland and/or other islands' [11:4]. This, Burholt and colleagues [11] suggest, is based on a need for the island to retain its uniqueness to attract migrants that might be lured by the escapism it can provide, and alternative ways of life than on the mainland. This outward representation of cohesion, however, renders invisible significant and tangible differences in islander identities [15, 23, 58]. Gill [23] goes as far as to say that rural Irish islands are actually inherently non-cohesive, as island dwellers embrace psychological distancing strategies to assert individual identities and independence to counter the homogenising identity that islandness ascribes. These strategies might include not walking to the part of the island that someone you've had a grievance with lives (sometimes for years), and a strong independence and self-reliance, which means that collaboration happens only when all other avenues have been exhausted, after which support is plentiful and forthcoming [23]. This contradiction between outward facing cohesion and inward facing lack of cohesion Watts calls the 'collective mask' and she suggests it is a form of strategic silence than enables collaboration 


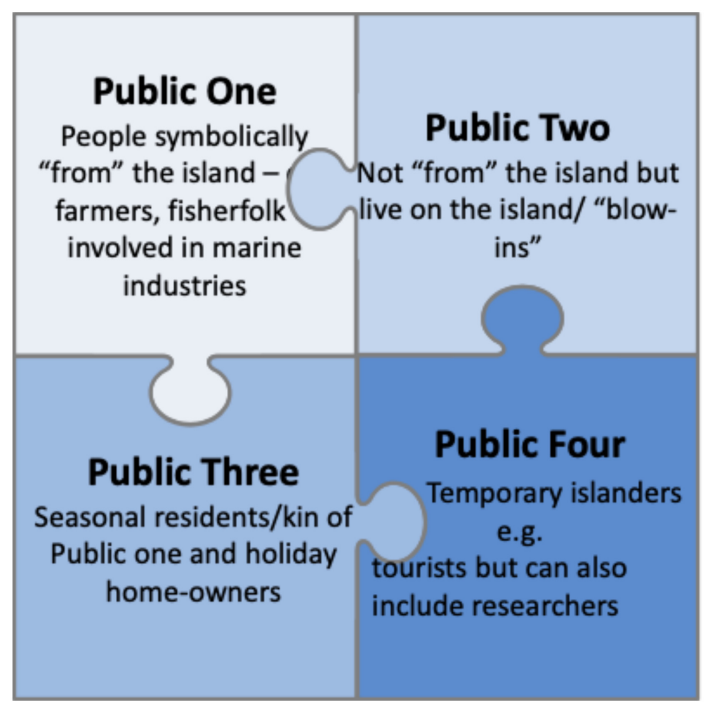

Fig. 1. Gill's publics.

to take place, stating: 'You sit on your tensions and stay silent because this is part of the work of wearing the mask and being part of oddkin'. [58:209].

For Gill [23] the need to foster independence and seek ways to distance from the homogenising island identity is partly due to an inability to escape the gaze of fellow islanders, due to publicness. The smaller the island, the more immediate publicness is experienced, by this we mean, that everyone knows who is on or off the island, and movements are often known by fellow islanders. In this context, Gill [23] considers identity as managed by the formation of four different publics depicted in Figure 1, each interlinked and acting as an audience for the other. Public One consists of people symbolically from the island. Public Two comprises emigrants (sometimes actively exercising separation from urban mainland areas and values through their migration). Women who migrate to marry someone from Public One often subsumes into that category, rather than gaining Public Two status, rendering previous identities invisible, which does not seem to happen in the same way for men [23]. In our experience, members of Public One are often involved in primary production activities whilst Public Two might maintain urban type jobs. Public Three comprises some seasonal dwellers and relations of those on the island [23]. Gill [23] does not specify but we assume he means holiday homeowners, and/or kin and relatives of Public One who live away from the island but remain part of the island community. While there are rivalries and tensions between Public One, Two and Three, they form one larger common public in the face of Public Four, anonymous visitors that often multiply in the summer months [23]. Boundaries between these publics are negotiated with care, and what can and can't be said is implicitly known by islanders. When individuals do not become aware of the boundary management conditions, they risk ostracism and social sanction that limits reciprocal collaboration [2, 23]. Any negative story-telling or dissent is particularly frowned upon for short-term visitors from Public Four [23], something we conclude that researchers as temporary members of the community must be particularly mindful of.

Lastly, we suggest that symbolic definitions of rurality as 'a discursive category from which people form attachments' [29:8] can be heightened for rural islands, as in the case in Ireland, where islands form an important part of the Irish collective consciousness as symbols of an ideal Irish identity, based on rurality [21]. This can be a resource and a constraint for islands, as they are 
positioned as culturally valuable heritage sites, but not necessarily as places of everyday yearround habitation. Gill [23] suggests that there are a number of different policy options which construct rural islands as either 'a nostalgic museum of rural life', 'summer play-ground', or 'retirement village' each with consequences for lived experience and potential futures creating positions for islanders to negotiate, support or resist [24]. New retirees, for example, may become staunch conservationists of the rural idyll and 'resist development favoured by less affluent locals', [25:156] and summer playground approaches can lead to empty holiday homes in winter as symbols of depopulation [34]. Globally and metaphorically, islands can also depict rural idyls and tropical paradises, as well as prisons [1], and in EU policy are represented as 'backward'. [41] These various discursive representations of the islands interact with rurality in the Irish context. Islands also symbolically connect with other islands, to work together on areas of common interest. In Ireland this involves a federation of islands called Comhdháil Oileáin na hÉireann, the Irish Islands Federation (http://oileain.net/), and in Europe, the European Network of Small Islands (ESIN) (https://europeansmallislands.com/), where islands benefit from lobbying and networking that can elevate their status beyond other rural communities in policy discussions.

\subsection{Rural Islands and Islandness in $\mathrm{HCI}$}

Having clarified our position on rural islandness in Section 2.1, our aim in this section is to link rural islandness directly to concerns in rural STS and HCI, in relation to values and research engagement in projects that involve the design of technology to support rural lives. To begin, Brynjarsdóttir and Sengers [10], Sengers [50] explore the relationship between the development of technology, values and the everyday experiences and lifestyles of islanders on Change Islands in Newfoundland. They found that, whilst technology is typically associated with 'progress' this is not always the experience for rural dwellers. For example, mechanization can result in the collapse of fish stocks and the end of fisheries and fishing communities [10]. However, by reflecting on urban biases and the potential unintended consequences of technology, it is possible to find technology that supports local cultures and values. Sengers [50] suggests that the defamiliarization of being on Change Island led her to novel ways of considering technology design more generally. Questioning the modernist norms of productivity, choice and efficiency that often go hand in hand with technology, Sengers [50] recognizes the value of not having choice and the importance of social connection and community, enabled through freeing her time and attention with fewer urban distractions. Small rural islands and connection with the weather, the land and the sea led to other priorities that are often not considered in technology design [50].

Whereas mechanisation has provided a challenge for fishing [10], local commitment to technological development results in quite different experiences and outcomes on the Orkney Islands. Watts' [58] ethnography of energy futures illustrates how Orkney islanders are amongst the world's leading innovators in the design of renewable energy technology, born from the necessity of making energy work in their remote location. From being an importer of energy, the people of Orkney have learned through decades of experimentation to produce more energy than they use. The first wind turbine in the United Kingdom was set up on the Orkney Islands and now Orcadians have turned the energy of winds into a reliable source of power. Now they are experimenting on energy storage solutions for a part of the UK that is closer to the Arctic Circle than to London. In the Orkney Islands, the rural island context is repositioned as a place of technology innovation and islanders are positioned as influencers and experts. In this way, design and technology is influenced by its usefulness in making living on the island viable and arguably better, and is based on the environment (the wind, the sea) as well as what is to hand [58].

Watts also reminds us of Kofi Annan's statement that 'islands are frontline zones where many of the main problems of environment and development are unfolding' [58:149]. Orcadians are 
acutely aware of their fragility where uninhabited islands now 'haunt' the seascape and depopulation within a generation is a very real threat $[57,58]$. Such experiences on islands have been called 'advance indicators or extreme reproduction of what is present or future elsewhere' [3:165] indicating that such islands illustrate potential futures for other rural areas, faced with urbanization and the climate crisis. In Orkney, a sustainable future (and future infrastructure's role in that) is not something abstract and detached, but rather it is a matter of concern for everybody [57, 58]. This has implications for how technology is received [57]. Watts [57] notes that resistance is not necessarily resistance to innovation, but rather it can generate innovation through the ways islanders improvise to make things work in their contexts. Such collaborations with designers are based on forging a sustainable future, and on place-making. If technology does not 'care for the longer-term, for the next generation of the community and place' [57:20] it will be resisted. This can often be the case if developers' timeframe is the shorter-term 'based on care for the next generation of products' [57:20], rather than on place.

HCI research also suggests that imaginaries of a sustainable future differ among the microcommunities on rural islands. Brynjarsdóttir and Sengers [10], for example, found dramatically different orientations towards heritage preservation on Change Island between Gill's Public One and Two. The latter were interested in aesthetically preserving old buildings once used for dying traditions like fishing, whilst the locals were not interested in preserving artefacts, but rather in reinvigorating lost social interactions that traditions once provided. For example, fathers who once passed on fishing traditions to their sons were at a loss when their sons moved away to the city. Once the reason for the social interaction was no longer there, the desire to preserve the way of fishing through writing it down, preserving artefacts that would no longer be used, was not there. As a designer, Sengers [10] reflects that her idea to apply ubicomp to heritage culture initially seemed straightforward; she intended to collect stories of islanders that could be replayed at the sites in which the stories had happened, through a ubiquitous tour for visitors to the island. However, through being in situ, she realised that this design only catered for urban residents sensibilities towards heritage, not for those 'from' the island, who were more interested 'for the culture itself to stay alive' [10:3], a reminder of the complex plurality of ruralities embodied on rural islands, and how the fragility of some ways of life can be threatened or not seen by technologies orientations.

Giglitto [22] found a similar dilemma on the Isle of Jura in Scotland. He tried to introduce a wiki developed with the intention of de-professionalising and democratizing the preservation of intangible heritage of the island. However, whilst wikis work well in other contexts, on the microsociety of the island, the open-access and anyone-can-edit functionalities threatened local ways of information sharing. Local islanders were resistant fearing the social consequences of allowing anyone to edit other's narratives could rock the social harmony needed for collaborative work to continue [22]. Giglitto [22] found Public Two much easier to engage with due to urban sensibilities and synergies, yet they were also cautious in their engagement, considered whether they had the right to tell or not, and feared any local consequences of their actions. They referred to locals as island 'Gurus' and these 'gurus' in turn would only share narratives they felt 'expert' in and did not see the point to the wiki, fearing consequences of its global reach might have, e.g., attracting more tourists. Both groups, however, did agree that the technology could be supportive in enabling those that now live off the island in fostering belonging [22].

Of course, the technology itself may not be the issue. Outsiders' encounters with islandness can be challenging, perhaps especially when the outsiders are HCI (and other) researchers and designers whose methods are inclined to intervene and at times perturb [10]. The careful negotiation in Giglitto's [22] study of who 'has a right to tell' shows the delicate care work engaged in by the different publics on the island to remain available to collaborate. HCI methods and/or technology 
can unintendedly amplify the voices of one Public over another more reluctant one [10, 22]. As the case of Jurapedia suggests, the methods and the introduction of technology have the potential to threaten the social practices of the island and risk publicly breaking the collective mask that Watts suggests is important for island solidarity to continue [22]. Where HCI has engaged most effectively in rural islands is through long-term collaborations based on mutuality such as Dix and colleagues' $[13,17-20,51]$ collaborations with Tiree islanders and Brereton and colleagues work $[8,9]$ with the Warnindilyakwa people of Groote Eylandt. Both start from a space of reciprocity and mutual interest and support the idea of islanding that Vannini and Taggart [54] espouse, essentially approaching research as collaboration in place-making. What HCI research on islands teaches us, then, is the importance of commitment to the place-making of the island, as part of research engagement, and it also challenges HCI's outsider-in approach [8], suggesting that we might need to reposition towards a commitment to island communities based on mutuality.

In this section, we have attempted to understand why previous technology projects located in rural island contexts have succeeded or not. Sometimes, as designers or researchers, our urban biases or indeed rural biases from other areas are not evident when we enter a space, but through interactions with the various publics, design assumptions become visible. Some technology projects were indigenous to islands (e.g., energy infrastructure on the Orkney Islands), others were developed as collaborations between islanders, developers and designers (e.g., Dix and colleagues work $[13,17-20,51])$, whilst others were initiated or imagined by designers, based on the representations of the rural that they brought to the rural island locations (e.g., Giglitto [22] and Sengers' [50] initial design idea). In these projects, islandness and rurality have been differently performed and symbolically defined, drawing attention to the need in $\mathrm{HCI}$ to appreciate and account for the indigenous framing of rurality and local identities, but also consider how design can influence rural pluralities in sometimes unintended ways.

The studies we described above also demonstrate that the set of methods from which we draw to do design research may be problematic. Regardless of theoretical orientation of the designers, design methods typically ask participants (or end-users, collaborators, etc.) to reveal something about their experiences, values, beliefs, or challenges. As we can see, islandness functions to constrain the ways in which people can do those things. Byrnjarsdóttir and Sengers [50] found that traditional research approaches are not favoured by Public One, and that the informed consent process of signing a form was alien to the rural island dwellers and not received well. Sengers realised that such processes are attuned to urban university sensibilities rather than rural ways of engagement [10]. For Watts [58], Byrnjarsdóttir and Sengers [10], trust is the foundation for all engagements, and this is earned through commitment to people and place. For example, Sengers [10] was trusted with information, to decipher what to share and what not to share as part of the research process, with islanders choosing not to formally make what they share part of research through signing consent forms. Instead, Sengers [10] was expected to use her researcher judgement to make the call on what shall be written and what shall remain unsaid. In this way, islanders reject colonising of local knowledge. Similarly, Brereton and colleagues [8] find that traditional 'outsider-in' approaches do not work on Groote Eyelandt, and that collaboration must be grounded in reciprocity. These issues are particularly salient in the encounters with islandness described in Section 3.

\section{METHODOLOGY}

\subsection{Background}

We describe a study within a larger EU-funded project, which has set out to examine the use of novel hardware and software technology to support rural communities in establishing low power 
FM community radio stations [14, 38]. The spirit of the project is participatory. The high-level ambition is to enable local communities to establish their own peer-to-peer radio platform, with low-cost technology investment, through the kind of voluntary activism that is seen as characteristic of community radio movements. There are community partners in The Danube Delta in Romania, the island of Madeira in Portugal, and small rural islands off the South West coast of Ireland. At the outset, we saw the project as community-driven and participatory on several levels. On one level, community partners and community members come together to make decisions about their own station, with some very urgent questions to answer, such as; where the mast should be located, how will it be powered and serviced, what content would the community like to broadcast, how often and for how long, who gets to participate in production and presenting duties. On another level, community partners are driving the development of the technology, by expressing the needs that it should fulfil, and reporting on how well it fulfils those needs. Supporting both levels of community-driven participatory design are a group of academic researchers with design, computing and psychology backgrounds. Our intention at the outset of the project was to support community decision making processes, and to ensure a line of communication between the values and experiences of communities and those of the software developers. While our team involved people with expertise in experience-based design, participatory design and cross-cultural design, none of us had worked on rural island contexts. Our initial engagement led us to realise the importance of islandness in ways we had not realised as central to the design process, before interactions with island communities. Similar to the work of Winshiers-Theophilus and colleagues in rural Namibia, we were 'participated' by the communities [59].

In this article, we focus on one of the rural contexts considered by the project, Island South. We have already mentioned in Section 2.1 how islands are considered culturally valuable as sites of heritage in Ireland, and the various different policy approaches that have been taken towards islands. While there are 362 small islands off the coast of Ireland, there are only 53 that remain inhabited [11]. Island South has a population of about 200 people, which often trebles in the summertime. The number of residents has constantly decreased since the Great Irish Famine in the mid-nineteenth century (in 1841, there were more than 2,000 people residing on the Island), and Island South shares a Bay with two other islands, one of which is now depopulated and another, with a dwindling population. The island is about $1.5 \mathrm{~km}$ from the mainland, connected by regular ferry service (about 15-30 minutes). Due to the heightened population in Summer, the ferry service tends to run more frequently than in Winter. The main activities are farming, fishing, associated marine support industries and tourism. The community partner involved in the Island South Team is a community development organisation composed of community members, who enthusiastically joined the project considering a community radio station as a good tool to support community development.

The University research team active in the phase of the project we report here was largely Irish and relatively new to small island living, apart from occasional visits. We did have enough experience of islands around Ireland to know that communication and access would be issues of concern that could, in part, be supported by community radio. We knew we were engaging with small rural islands that are sparsely populated, sometimes cut off from the mainland and not well served in terms of communication infrastructure. As we will see later, our problem-based, functional, technology-informed assumptions about the needs of islanders missed some important social characteristics of island living.

While the community considered using the radio production and broadcast system suggested by the EU project (RootIO), they chose another radio system that better aligned with their goals [46]. Essentially, their radio content was broadcast on FM, which enabled the community to broadcast within a specified geographic region. FM transmission opened opportunities for those on the Island 
Table 1. Dates of Field Trips for Ethnography

\begin{tabular}{|l|c|l|}
\hline Dates of Field Trip & Number of Days & \multicolumn{1}{|c|}{ Authors Present } \\
\hline August 2018 & 5 & LM \\
\hline & 2 & CL \\
\hline January 2019 & 5 & RC, CL, LM, JMc, NP \& SR \\
\hline February 2019 & 4 & SR \\
\hline March 2019 & 5 & SR \\
\hline May 2019 & 3 & SR \\
\hline & 2 & LM \\
\hline August 2019 & 2 & SR \\
\hline October 2019 & 2 & SR \\
\hline November 2019 & 1 & SR \\
\hline
\end{tabular}

to connect with people both on the Island and on the coast of Ireland. There was the opportunity to stream the radio online; this allowed community members based elsewhere to listen to and actively participate in the radio. Unlike FM, internet streaming does not have predefined geographical barriers for transmission. Additionally, the broadcast is public to anyone who either has access to the FM frequency and FM radio (for FM) or the internet link, a device for accessing the internet, and an internet connection (for internet streaming).

\subsection{The Current Study}

In this article, we focus on identifying specific characteristics of small rural islands that influence how inhabitants engage with research and design processes and, in turn, how technology projects align (or not) with their needs and aspirations, through a case study of Island South. We seek to understand how islandness impacts upon engagement in an HCI project in Sections 4.1 and 4.2, and how islandness impacts upon technology deployment and appropriation during the project in 4.3. In the discussion, we will make recommendations for others working in rural islands, but also rural areas more broadly.

Data analysed in the article comes from two sources. Firstly, we conducted semi-structured interviews with community members (as described in Table 2) in the early phase of the project on Island South staggered from August 2018 until April 2019. While we gave people the option for interviews to be conducted via phone or in their home, those that participated opted to participate in community spaces, giving the appearance of a casual conversation to those that might pass by. Having a researcher's car visible outside their house made it more 'obvious' they were engaging in the research process, or more public, than having a conversation with the researcher in a public community space. The first author conducted most interviews and the fifth author conducted two interviews. Our questions in these semi-structured interviews included: What does the island mean to you? What are your favourite things about the island? Has the island changed much in your lifetime? How would you describe a typical day for you? Where do you get trusted information? What local media do you use?

Ethnographic field notes from the first and fifth author were also taken and used as supplementary material for the thematic analysis. Field trips took place between August 2018 and November 2019, as indicated in Table 1. Visits to the island took place for a number of reasons; to participate in events that launched and promoted the radio station, to gather data on the practices and interests of islanders with regard to radio consumption, to help plan and participate in training events, and to carry out interviews. We recorded written notes, in notebooks, and took photographs. In 
Table 2. Participants by Gender, Age Range and Publics

\begin{tabular}{|l|c|l|}
\hline Gender & Public & \multicolumn{1}{|c|}{ Age Range } \\
\hline Male & 4 & Middle-Age \\
\hline Male & 3 & Middle-Age \\
\hline Male & 3 & Middle-Age \\
\hline Male & 3 & Middle-Age \\
\hline Male & 3 & Middle-Age \\
\hline Female & 3 & Middle-Age \\
\hline Male & 2 & Middle-Age \\
\hline Male & 1 & Middle-Age \\
\hline Female & 1 & Young \\
\hline Female & 1 & Middle-Age \\
\hline Female & 1 & Middle-Age \\
\hline Female & 1 & Middle-Age \\
\hline Female & $2^{*}$ & Middle-Age \\
\hline
\end{tabular}

*subsumed into Public One through marriage, as Gill [23] similarly observes in this ethnography.

addition, we had regular contact with 'islandpartner' through bi-weekly jitsi calls, and regular phone calls ${ }^{2}$.

3.2.1 Privacy and Informed Consent. We obtained ethical approval for this work from the Social Science Research Ethics Committee of University College Cork. Similar to what Byrnjarsdóttir and Sengers [10] found, most people that participated in formal interviews did not feel comfortable with the informed consent process, questioning the information sheet and the manner in which the answers to their questions could be used. In order to make the process better informed, and to support local concerns about the publication of our data having local consequences (which were heightened given the small geographic confines of the island), we gave transcripts of interviews to participants who requested them, to remove anything they wish they had not said and guide us on local sensitivities that we needed to be mindful of in writing up our research findings. In particular, the anonymization of data was challenging in this type of small world setting, and as a result identifying features have been removed, whilst maintaining the integrity of the narrative [49]. We also observed that the sensitivity to potential local consequences of action was primarily expressed by those from Public One and Public Two, rather than Public Three, indicative that potential consequences were linked to living on the island. Field notes were also prepared by the first author and fifth author on visits to the island.

3.2.2 Data Analysis. We audio-recorded eight of the 12 interviews. Four interviewees preferred not to be audio-recorded and the first author took notes of the interviews and shared with the participants for accuracy. We used Braun and Clarke's six-step process of reflexive thematic analysis. These six stages involved are (1) familiarizing with the data through reading and rereading, (2) coding, (3) organising codes into themes, (4) reviewing and refining themes, (5) defining and

\footnotetext{
${ }^{2}$ In October 2019, the first author coincided a visit to Island South with a visiting $\mathrm{PhD}$ candidate from the University of the Highlands and Islands, Fleur Ward. In order to minimize community disruption we had a joint conversation with radio volunteers. This conversation was audio-recorded and transcribed by Fleur and shared with the first author. It also forms part of Fleur Ward's data collection for her forthcoming $\mathrm{PhD}$ on the role of technology in the governance of the Scottish and Irish islands. For more information, see [56].
} 


\section{Experiences of Rural Islandness}
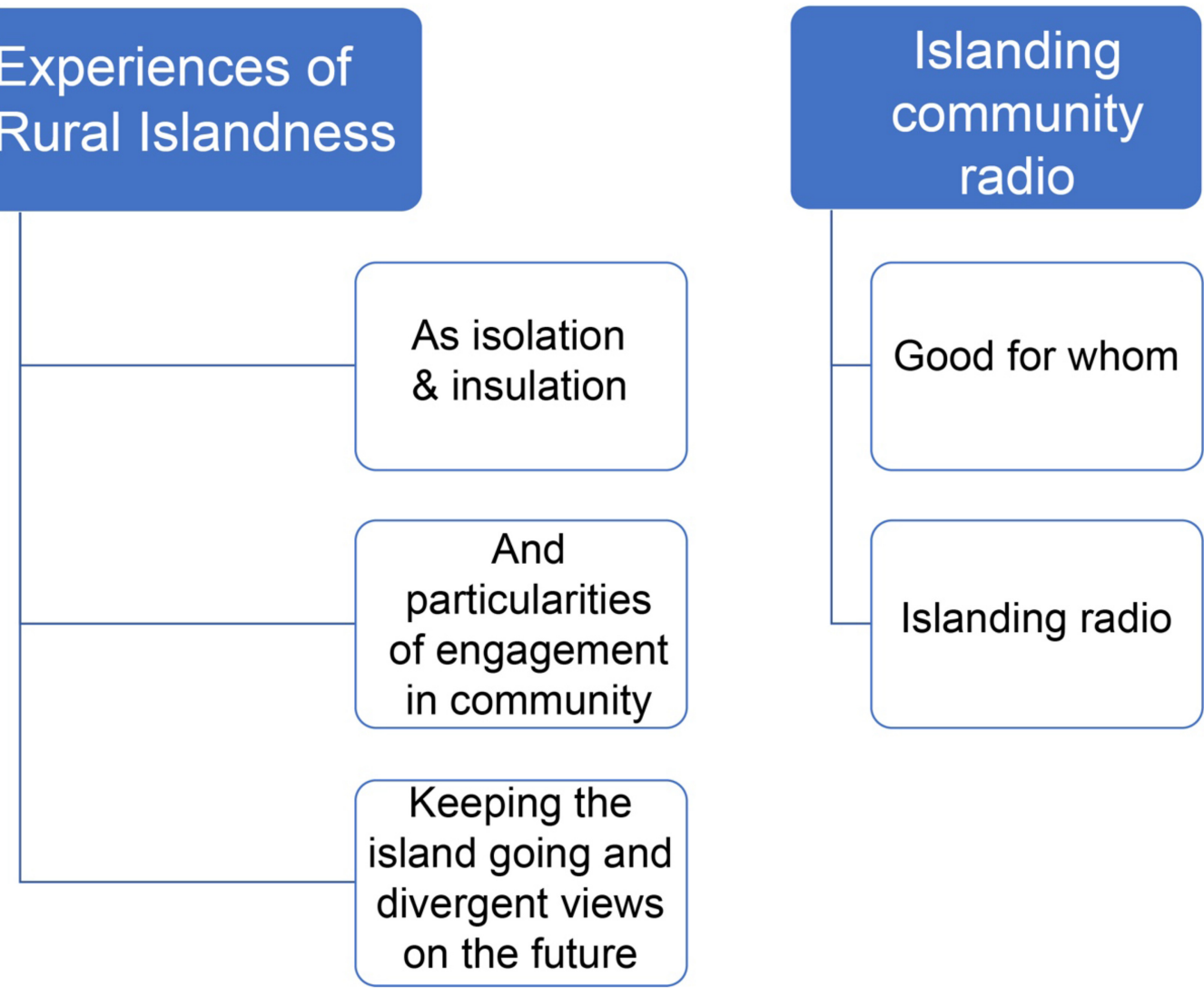

Fig. 2. Thematic map.

naming themes, and (6) writing of the report and contextualising the analysis in relation to existing literature. We found writing to be an important stage of the analytic process, where all authors contributed to the central meaning of each theme. These six stages were recursive rather than linear. Stages 1 to 3 were conducted by the first author, with stages four to six shared with co-authors.

\section{FINDINGS}

In this article, we focus on identifying specific characteristics of small rural islands that influence how inhabitants engage with research and design and, in turn, how technology projects align (or not) with their needs and aspirations, through a case study of Island South. Our findings are presented in the form of two core themes of (1) Experiences of rural islandness and (2) Islanding Community Radio. Each theme has a number of sub-themes, as illustrated in Figure 2 and Table 3. Our first theme presents the experience of living on an island, specifically around the qualities of insulation and isolation, which in turn informs patterns of community participation (e.g., 'pushing things ahead' and 'keeping the peace'), volunteering and differing views of the future of the island. In our second theme we describe how these experiences of rural islandness have specific implications in the development of a project of technology co-design, presenting the case of 'Islanding Community Radio'. We will show how the specificities of this contexts influence how islanders consider and engage with the design process, the actors involved, the radio technology setup and 
Table 3. Values and Social Interactions Related to Thematic Analysis

\begin{tabular}{|c|c|c|c|}
\hline Theme & Sub-theme & Values & Practices \& Social Interactions \\
\hline \multirow[t]{9}{*}{$\begin{array}{l}\text { Pushing } \\
\text { things ahead } \\
\text { and fear of } \\
\text { change }\end{array}$} & $\begin{array}{l}\text { Rural islandness as } \\
\text { isolation and insulation }\end{array}$ & $\begin{array}{l}\text { Connectivity at times, } \\
\text { but valuing } \\
\text { disconnection }\end{array}$ & $\begin{array}{l}\text { Ferry-dependencies } \\
\text { Preparedness and planning }\end{array}$ \\
\hline & & Community & $\begin{array}{l}\text { Meitheal (old Irish tradition } \\
\text { where people gather together } \\
\text { and give support during } \\
\text { harvest or when there is } \\
\text { calving-it is a form of } \\
\text { reciprocity). }\end{array}$ \\
\hline & $\begin{array}{l}\text { Rural islandness and } \\
\text { particularities of } \\
\text { engagement in } \\
\text { community }\end{array}$ & Development & $\begin{array}{l}\text { Public Two dominance in } \\
\text { decision-making } \\
\text { Difficult for some in Public } \\
\text { One to talk } \\
\text { Formal committees }\end{array}$ \\
\hline & & $\begin{array}{l}\text { Enjoying leisure } \\
\text { time/Ruralscape }\end{array}$ & $\begin{array}{l}\text { Disinterest in } \\
\text { decision-making/community } \\
\text { schemes }\end{array}$ \\
\hline & & $\begin{array}{l}\text { Importance of feeling } \\
\text { heard/genuine } \\
\text { participation }\end{array}$ & $\begin{array}{l}\text { Non-participation versus } \\
\text { participation } \\
\text { Formal committees }\end{array}$ \\
\hline & & Islandness & Ferry-dependencies \\
\hline & & $\begin{array}{l}\text { Social harmony, } \\
\text { reciprocity and } \\
\text { politeness }\end{array}$ & $\begin{array}{l}\text { Non-participation/'sitting on } \\
\text { your tension' }\end{array}$ \\
\hline & $\begin{array}{l}\text { Keeping the island } \\
\text { going and divergent } \\
\text { views on the future }\end{array}$ & Publics & Divergent public views \\
\hline & & $\begin{array}{l}\text { Internalization of being } \\
\text { a 'number' }\end{array}$ & $\begin{array}{l}\text { Immigration needs yet fear of } \\
\text { immigration } \\
\text { Gendered pressures } \\
\text { Inter-public tensions around } \\
\text { futures }\end{array}$ \\
\hline \multirow[t]{2}{*}{$\begin{array}{l}\text { Islanding } \\
\text { radio and } \\
\text { content }\end{array}$} & Good for whom & Social inclusion & $\begin{array}{l}\text { Watch and wait approach } \\
\text { Non-participation } \\
\text { Diaspora engagement }\end{array}$ \\
\hline & Islanding radio & $\begin{array}{l}\text { Pragmatic Artful } \\
\text { integration and } \\
\text { reliability }\end{array}$ & $\begin{array}{l}\text { Importance of maintenance } \\
\text { and repair } \\
\text { Importance of relationships to } \\
\text { sustain technology }\end{array}$ \\
\hline
\end{tabular}


content that was produced. We aim to illustrate what types of social interactions, affordances and constraints are enabled through living on a small rural island, and how these might relate to the community radio project we are involved in and to HCI more broadly (in our discussion section).

We do this through using Gill's analytic tool of publics to indicate the differing speaking position of those we encounter, as either Public One, Public Two or Public Three-these overlap and equate with local terms of 'islander' for Public One; 'Blow-in' for Public Two and 'Returning Families, Diaspora or Second-home owners' for Public Three. Public Four in our use is indicated for anyone that is a stranger to the island, that does not live there or work there full-time but contributes to the EU project and the community radio or is a tourist. These different Publics are in turn referred to throughout the findings through the abbreviation P1 for Public One; P2 for Public Two; P3 for Public Three and P4 for Public Four.

\subsection{Experiences of Rural Islandness}

Just as Vannini [53] found that islanders experience their separation from the mainland as both isolating and insulating, we begin with a theme that presents the experience of living on an island, specifically around these qualities of insulation and isolation, which in turn informs patterns of community participation, volunteering and decision making and has implications towards islanders' engagement with the design process and the radio setup (as presented next in Section 4.2). This boundedness of the island, being insulated and isolated, accounted for a strong community spirit amongst the islanders, but equally made engagement in community roles, decision making and 'pushing things ahead' challenging in a number of ways.

4.1.1 Rural Islandness as Insulation and Isolation. Our analysis captured two unique island qualities, both contrasted to the rural mainland and discussed across all publics: insulation and isolation. Insulation was characterized by attributes such as simplicity, stillness and a slower pace of life, whereas its flipside isolation, (both physical and social), was about the sparseness, the separateness and the hardships of island life.

For those from Public One, Two and Three, insulation was discussed as the key motivator for island living, as Kitty (P1), Anne (P1) and Mark (P2) explained. Ferry-dependency rather than connection to the mainland by bridge was something valued and sought after, that enabled a certain type of lifestyle that the always-on connection of a bridge might erode. For Mark (P2) an island resident for over twenty years, this was related to a perceived preservation from change created by islandness:

It hasn't changed one bit. The population hasn't changed. the place hasn't changed. Nothing has changed [...]. And it's not going to change [...]The day they built a bridge to the island will be the day that I leave. Cos then it's not an island.

Others explained those who moved to the island and decided to leave after several years, often moved to another island, suggesting the quality of being cut-off from the mainland was important to them.

Everyone talked about the beauty of the island, the ruggedness, its views, the scenic walks and the slow pace of life as things they valued, as well as constantly being surrounded by the sea. One member of Public Two, said, 'affinity with the sea' was a reason why he loved the island so much. Both the soundscape ('the peace and quiet') and the rural island views were important to almost everyone we interviewed or encountered. The contrast between the tempo of life on the island versus the pace of life in the corresponding rural mainland town was emphasized, for example, by James (P2) as follows: 
I'm sure you notice that if you spend a couple of days here, em so yeah, it's peace and quiet, which is very attractive to me, and lots of other people who love that feeling of eh isolation... it eh... slow down. So, I often said to people who have been working here, that time goes slow but fast. If you understand that, that means that the days melt into the weeks and weeks melt into months and melt rather than just... because in one 24-hour period... you don't... you're not like any city or town where you visually see things all the time and you're you know, there's things happening all the time.

The flipside of insulation was the quality of isolation, social and physical. Here, Public One and Two alike discussed the hardships of island life, suggesting that it is not for everyone. The darkness of winter, being cut-off and surrounded by sea was a challenge, with stoicism, planning and preparedness required, when the weather meant the mainland could not be accessed. It also meant limiting options to mainland activities such as night courses in Winter, when the ferry timetable was reduced due to the lack of commercial viability, meaning that some could not access evening courses or other opportunities. Patrick (P2) suggested that if the island is not for you, you will not survive a winter, he described being visibly cut off in mist and the days being dark and long:

It either suits you or it doesn't, there's no in-between, because it is very isolated. It hasn't changed, it's rugged, it's sparse, it's basically like that. We've a few more houses here or there, that's it. As regards, the population has gotten smaller, but I suppose the actual terrain... the tranquility and the peace that you actually can get here, it has to suit you.... It's not for everybody. [text removed]. The one thing you will not do, you will not do a winter on the island here and come back next year if it doesn't suit you. That's definite... last Sunday, it was a shocking morning. You get mornings and you get days like that and you know, if that, if that's going to affect you, and it will, it will, not everyone's cut out for it. But once you're ok with that, and once you're happy and you're ok with that, and pace of life. [Gestures to suggest that life is good.]

This isolation was also particularly felt when there was a crisis or emergency, as the island relied on mainland services in crisis. Fires had ravished some homes and a local business in living memory, and others spoke about medical emergencies. As Damian (1) stated the following:

The obvious concern would be getting off the island, weather is obviously a big factor. It's quite isolated, not as much as the other islands, but in emergency situations, it can be tricky. We've had to call the emergency helicopter a few times-they land on the GAA pitch and bring people to hospital if necessary.

But at the same time, those same challenges of isolation strengthened the community spirit and support experienced by islanders and this was repeatedly mentioned as a top reason to live on the island. Community was also evident when people checked-in on others during emergencies, and when Betty (P1), for example, ensured her business premise provided a space for social interaction and companionship, even when it wasn't commercially viable.

Community was particularly evident during times of need such as shared farming activities, grief and emergencies. Damian (P1) for example says the following:

Generally, if there is a funeral everyone will congregate and we're all on the same level that way. Kinda morbid in a way. If anyone is in trouble with an animal like a cow people will rally around. 
These strong community bonds were also, interestingly, described using the metaphor of a family bringing forward the positives and negatives that come with such a close, usually non-chosen relationship:

Yeah, so I feel like that can be a blessing and a curse at the same time. So, in times of difficulty everyone's there... coming together supporting each other...then when you're celebrating... everyone is celebrating with you as well, but at the same time everyone knows everything so that can be difficult. Marie (P1)

These close, almost family-like, bonds between islanders, in combination with the qualities of isolation and insulation described earlier, shaped a unique experience of publicness of island life and in turn participation in community roles and broader community initiatives.

4.1.2 Rural Islandness and Particularities of Engagement in Community. This boundedness of the island, being insulated and isolated, accounted for particularities in decision-making and participating in community life which in turn shaped islanders' engagement with the design process and the radio setup. While (as presented above) community spirit was strong, engagement in community roles and development decisions was challenging and less subscribed to due to the publicness of the island and a heightened sense of located accountability to the community.

In general, there were few volunteers for community activities and in community decisionmaking and these tended to come from Public Two, with some notable exceptions from Public One. Mariam (P1/2) for example, talked about a core group of people who were involved in community activities and 'pushed things ahead', whilst many others did not actively participate. Patrick (P2) describes this as a dilemma of community, where there is a strong sense of community spirit in times of need, and emergency, with a tendency not to participate in broader community initiatives. He states the following:

...there's a nice community here but there's a contradiction then, $\cos [\ldots]$ at times, there's a lack of community spirit [...]like people, never leave one another ddown. $[\ldots]$ so if someone gets sick or if they need anything, you know? There'd always be someone. And that's one of the good things[... they'd call, and they'd give people a hand calving [...]But I suppose overall for pushing things ahead, and for moving ahead like you know, wouldn't be that strong here. Alright, lots of people on the island wouldn't get involved, and then you'd have certain families... involved.

Some considered Public Two as dominant in community decision-making, whilst others described them as highly educated and sharing this knowledge and skills, perhaps indicating a difference in the formal educational attainment amongst the Publics, which led to different ways of engaging in community. The reasons Public One did not participate as much as Public Two remained a mystery to those seeking to foster inclusion. A number of potential reasons were given by interviewees. Firstly, some people were apathetic and not interested, seeking to enjoy leisure time, or disliking the formality of island decision making ('There is a committee for everything'. Mariam P2). Secondly, Ben (P3) suggested that people might not participate due to embarrassment, and fear of being ridiculed in some way, indicating a heightened awareness of what others think. He states the following:

And you know, it's all about taking risk and that chance because, em, again, a lot like rural Ireland, and small communities, like where I was brought up in, there's this, like people don't want to embarrass themselves, and they care what people think, you know, and that's a biggie. Gossip is big, obviously like on islands, you 
know? When you're first in, people will say to you, 'Any news?' or 'Anything strange?' or 'Any news for me?'

Thirdly, there were conflicting views of community development that ranged from supportive to fear. Some members of Public One felt that they were not involved in decision-making but rather were informed of decision-making, whilst others felt listened to and supported.

Fourthly, volunteering had reportedly declined since the professionalization of community development roles, in the past twenty years. Ben (P3) describes locals refusing to do roles that they believed should be the task of paid community development staff, saying things like 'No actually, you can do this tonight, you can do that' ... or 'No that's your job'. indicating the community monitored community development roles in some way. There was also an element of volunteer fatigue, with limited numbers of people on the island for the ever-expanding community initiatives and roles. Damian (P1) for example, laughed about the need for caution in stepping forward as a volunteer as if you were not careful you would still be volunteering 40 years later. Others talked about 'serving their time' and passing the 'baton' onto others, as a rationale for not engaging.

Finally, participating in community decision-making in the context of a small rural island meant taking a public position, which could be difficult given the micro-society of the island and this was managed through a process of keeping the peace to maintain social harmony. Public One were generally concerned about how their views might misalign with others, particularly, with influential community members, for example, the ferry operators who were considered a lifeline that enabled people to get on and off the island, or local businesses that made living on the island feasible. As Ben (P3) suggests-'You fall out with the ferry people and they can make it hard for you'. and John (P1) states, 'There are important relationships to maintain'.

There is a need to keep the peace and maintain social relations that influence people's engagement and social interactions in community initiatives. Sally (P1), for example, chose not to participate in community decisions, feeling that her role as a business owner rendered it too difficult to express her views. She explains the following:

Well they eh...they meet, they have meetings in the community centre. Now, I myself....

[...] I cannot...I'm here in the [local business] and I have to stay neutral [...]It's bad for business. It's... what people do is private... and you have to be there for people... and you must be discrete, you know? [...]People depend on you, d'you know? ... to be discrete...

Sally (P1) stresses the importance of privacy, discretion and neutrality, part of a care that islanders take in not openly upsetting others and keeping the peace, but this has implications for engagement in community.

This subtheme presented the particularities observed, such as pushing things ahead and keeping the peace, in islanders' (low) participation in community life and accounted for potential reasons behind those. In the next subtheme, we show that while all islanders were equally concerned about ensuring the future of the island ('keeping the island going'), there were differing visions about what this future should look like and what needed to be done.

4.1.3 'Keeping the Island Going' and Divergent Futures. As we see in 4.1.2. not all islanders supported 'pushing things ahead' and the visions of the future that community development advocated. While there were differences between the Publics in 'pushing things ahead', almost everyone was concerned about the future of the island and the declining population. There was also a constant reference to islanders as 'numbers', used either as a way to talk about the dehumanizing impact of State policy on rural communities (as Sally (P1) suggested, 'You're just a number to 
them in Dublin') or as an internalization of the collective pressure to have 'numbers' for essential services, often spoken about in terms of women's ability to provide children that could sustain the island community.

Community services deemed important for community viability were the Church, local businesses particularly those that enable social interaction and the school. Losing any of these services was something that could threaten the identity of the community and its future. Patrick (P2), for example, talked about historic policies of resettlement, deliberately targeting symbols of community such as the Church, to encourage people onto the mainland. He suggested that this history of resettlement haunted islanders and made them different. Marie (P1), who was undecided as to whether she wanted to stay on the island or not, keeping the school open was also important, as well as attracting more people to settle down, seeing in-migration as key to sustaining the island.

Interviewees were also concerned about the island not being economically viable or attractive for their children or younger generations who would likely leave for the 'bright lights' of the city and for 'good jobs' after college. Damian (P1) mentioned a missing generation ('Lack of numbers between 20, 30 and 40') and others mentioned an elderly aging population without younger generations to care for them. As Sally (P1) states the following:

Sally: Our numbers. Actually our numbers are falling. A lot of elderly people. And when they are gone then, they're gone. When they go, there's nobody there.... Sarah: coming up behind them?

Sally: No, no. A lot of elderly people are on their own and it's just scary really.

'Scary' also indicates the fear of losing island culture and community, within a generation. However, there were differing visions of what that future should look like. There was a perceived tension between the island representations that community development initiatives supported, and some of the realities Public One supported or resisted. For example, Public One generally supported the centrality of primary production rather than tourism. However, some felt that tourism was more widely supported by community development. Kitty and John (P1), for example, wanted more emphasis on 'islander interests' (described as housing, employment, ferry timetabling and support for primary production [farming and fishing]). For them, prioritizing these needs would help keep the community alive. As Kitty (P1) suggests the following:

Farmers and fishermen need our help they are the ones that will help keep the island going (Kitty, P1)

For Kitty, 'keeping the island going' referred to the need to have a vibrant community throughout the year, not just in the summer season. For Kitty (P1), John (P1), Sally (P1) and Annie (P1) representations of the island as a tourist destination or a summer playground had real world consequences. Tourism went hand in hand with an increase in Public Three (often second-holiday homeowners) and as a result a decrease in housing stock for year-round residents leading to a demographic change that limited social interactions outside of the summer season and threatened the viability of other services like the school. Ferry-timetables were also seasonal; expanding based on market demands in the summer and contracting in the winter, limiting access to things like evening classes on the mainland in the Winter. Some in Public One would rather ferry timetabling was based on need rather than market forces. Members of Public Three, such as Ciara and Liam (P3) also talked about finding it challenging that services such as the café were not open year around (as they were no longer viable outside of the tourist season). Sally (P1) also talked about the vulnerability of relying on tourism for her small business: 
it's, you have a very short season... you might... you get six, maybe six, seven good weeks... d'you know? That has to keep you going for the whole year.

Yet others saw tourism as central to the future of the island, as Patrick (P2) states the following:

Well I suppose one thing the islander has to take on board, even though they probably aren't taking it on board, they resent it a little, and that's tourism, you know? They want their island for themselves. But... if the island is going to sustain...there's great opportunities here.

In this sub-theme we have learned that there are differing views about the future of the island, which likely contribute to the lack of participation of some in community development. Overall, in this first theme, we explored the experience of rural islandness, which in turn shapes particularities of community participation and has implications towards islanders' engagement with the design process and the radio setup as it will be presented in the next section (4.2) as part of our second theme on 'Islanding Community Radio'.

\subsection{Islanding Community Radio}

In this theme we focus on both islandness and islanding, that is the making use of what is around you to make life livable and easier in the island context. We initially discuss how earlier themes come together in islanders' considerations of the radio technology and what it means for them and their lives, before exploring islanding that takes place during deployment of a prototype for radio, and the content that it elicited.

4.2.1 Good for Whom. In this sub-theme we explore considerations amongst the island community when the technology was being deployed, when they are considering who the radio should be for and whether or not it would be valuable or align with their goals and interests and representations of the island.

Radio for Islanders: In interviews, most people felt that the community radio would be a positive initiative, but very few were initially interested in participating in it. There was a sense through their positioning of the radio that they considered it would be a service to them, rather than something they would participate in. Kitty and John (P1) for example, talked about all the issues that faced them as islanders but explained it would be difficult to talk about them openly on the radio:

It's difficult to say these things.... It would be great if people felt it was their radio station and they could voice an opinion, but it's hard to say these things on an island. Keeping the peace is the challenge. This means that saying what you really think is very difficult.

Thus, indicating that the aspect of islandness considered in the theme Rural islandness and particularities of engagement in community might impact engagement. They were concerned about how the community radio could be used and which Public it might support? Drawing on the challenges of islandness they suggest the following:

Like we don't know what it will bring. Is it to promote the community abroad?

Will it bring more tourists? Or will it be about local interests? (Kitty and John, P1)

For some islanders (from Public One) participation in the radio was not forthcoming as, 'it must benefit the whole community' and until they could see that that was the case, there was 'fear of the unknown', which created a kind of watch and wait approach before taking part and having a say. Others (P1 and P2), however, expressed not being interested as they valued their solitude and peacefulness on the island and had no desire to get involved in other activities. For some of Public 
Two, the community radio station offered an opportunity to engage in the community. As Mark (P2) stated in response to a question about whether he'd be interested in the radio:

Not particularly one way or the other. It won't impact my life one way or the other.

Others questioned why a community radio, when what they really needed was Broadband, indicating a frustration with the project approach, where the development group opportunistically and pragmatically engaged with projects that could align with their work-plan. However, this approach was often top-down coming from external bodies, such as universities or the EU, and did not always reflect local priorities, reflecting the discursive tensions we unpack in the sub-theme Rural islandness and particularities of engagement in community.

Radio for the diaspora: Many felt that the community radio would most benefit those living off the island or Public Three, described as the 'diaspora' or 'returning families' rather than Public One, a point that some were worried about, whilst others were supportive of. Marie (P1), for example, suggests that islanders already know what is happening on the island through word-of-mouth, so the radio may be more useful for those living away:

I think it's a great initiative. Because so many people come to the island when they don't

actually live there so having that platform available, if it was online or something like

that...could be really interesting.... And eh...I think definitely it would have a listenership...I think maybe for island people themselves I'm not sure, it will be as useful, as it will be for people who aren't living on the island. Because I don't know.... I mean if people already know the news...I don't know whether they are going to be listening to it again... but I know if I was [away] I'd definitely tune in but if I'm at home I'm not sure if I would.

Patrick (P2) also suggests it is those in the diaspora that will engage initially rather than permanent island residents, who we have already explored might adopt a 'watch and wait' approach. For Patrick (P2), including those in the diaspora as part of the community radio platform would kick-start it, and if successful, others will follow:

Yeah, so if it's started by someone and then move on. People will probably come on board... Like if you can make it interesting... Interesting now is only some community base... Initially you'll have a better hope with the diaspora... That would be the people who are from the island but are away all over. They are still a core group of people who would have emigrated. You're probably running short a bit but like...ok, but like, some younger people have gone now as well, and you'd be surprised like, how, as I said, island people who are affiliated all over, they love island news, and if you could, if you could start off....[with them]

So, there was a dilemma in that those that were deemed more readily available to engage were from Public Two and Three respectively, 'blow-ins' and 'diaspora' rather than islanders. Yet 'islanders' would also watch and wait to see if the radio promoted a vision of the island that they could relate to and support.

Public meetings about the community radio were poorly attended and only people from Public Two participated on the Community Radio Committee.

4.2.2 Islanding Radio. Islanding in the sense of making use of what is around you to make life easier on the island was evident in the response of the community to deployment and 
piloting of a radio technology prototype. When the technology was deployed to Island South in early January 2019 the weather conditions were not favourable to erect the hardware of the mast and antenna, and it was not until March that the weather and conditions enabled volunteers to erect the hardware. Island South partner had a number of google hangout introductions to the software technology in the meantime and they were set to launch their radio station in March 2019. The location for the mast and antenna was the highest point on the island to enable radio to be transmitted to every house on the island and to reach the surrounding mainland peninsula. The software radio platform was housed on an Android phone connected to the transmitter, housed in a plastic bucket beside the mast and antenna. The phone was essentially the community radio station with communication to it achieved through the mobile phone network and cloud infrastructure.

However, communication broke down between the developers and the Island South team just before the first broadcast, when high winds snapped the mast in two. The community believed that the fibreglass mast that the developers had procured was not suitable to their island context, which was exposed and regularly received high winds. They sourced an aluminium mast as a replacement from a local community radio station. Then for the first broadcast, the community felt that the prototype of the radio platform didn't work, and there were problems with the phone. As Owen (P4), neighbouring community radio supporter says the following:

Em the one thing that I would say in regards, to I suppose remote sites, em, and eh like having a phone that's up a hill that's going to take half an hour to an hour to get up defeats the context if you are actually doing a live programme at the time. That you don't have that time available to you, you want to get in and see what is going on in the system

As a result, in a rainy March, volunteers had to drive up in a four-wheel drive or hike to refresh it. Having to go up the hill to fix problems, whilst also trying to meet regulatory demands and community expectations was challenging and was not what the community development organisation had expected. At a community radio meeting a representative (P2) said the following:

The community thought that this project was all about community needs, and supporting the community to set up radio, we assumed the technology worked. We were told it had worked in Uganda-why isn't it working here?

Island South team were not happy that piloting would take time to make things work. During one community radio broadcast the phone went down three times, leading to frustration. They also feared not having expertise to sustain the technology beyond the future of the project, and from early on, were concerned about the level of support they would get into the future. At our January meeting, one Island South Team member asked, 'What happens when the project is over? Who will support us when there are problems with the technology?' He was told the support would remain the same and he became quiet, 'sitting on his tension.'

After their first broadcast in March 2019, Island South Team paused piloting of the novel technology and found workable solutions locally for radio, in short, they opted to island radio deeming the prototype not stable enough for their needs. The island context illustrated the importance of being able to interact with the technology without travelling up and down to the transmission site.

For the Island South Team, the fact that the technology was not yet working as they had hoped, when they were under the gaze of other islanders, whilst also having to honour broadcasting requirements, was too much. For Martin (P2) the importance of the reliability of the technology that the community group were piloting was related to respect of the community. He states the following: 
It is either we get the radio up and running or we wait till its [the platform is] stable. We have no problem in using a stable system-you can't build a community radio station on flawed technology. Streaming songs with it is fine, but when you are doing interviews with people about their stories, it's really important to them. Like last Sunday we ran over time, and we had to contact Brendan (P4) to ask who's going to get cut? Who won't mind not being on this week? You can't do it...you can't have people's interviews dropping off because the [platform] isn't reliable. It's important to respect the community when someone puts in the time.

Martin (P2) refers to a need to respect people's stories and to ensure there is a reliable broadcast so that voices are heard. The challenge in the publicness of the island is building a community audience for radio, whilst also piloting technological solutions to make radio work. Volunteers (all P2) were concerned about how people would sound on the radio, and how the radio would be perceived. They were also particularly concerned with how it would outwardly reflect collective identity, and wanted the community to feel pride in it, and for it to be a source of community pride. There was care in considering how people might sound on the radio, and efforts put into editing interviews to ensure that people sounded their best self. As Martin (P2) says the following:

taking out all the Ems and coughs, etc. Making people sound good in front of their community is important.

Owen (P4) stated that there were expectations of professionalism due to the strong history of radio in Ireland, and he explains that the need for a reliable technology to enable broadcasting is important. As he (P4) stated the following:

[in Ireland] there is a high level of expectation among people who listen to radio for quality, [...] if you have something that's not reliable, that's not there when you say it's going to be there, or you have breakdowns or whatever, then people will lose interest and very very quickly, and I think that's vital and I think that that was partly probably the initial confidence issues in the context of our station with the platform.

As a result, volunteers sought support from professionals with expertise in journalism and radio to realize radio that was reliable and had a professional quality. As Ciara and Liam (P3), members of Public Three told us the station is still competing against more professional services. Ciara gave an example of a podcast run by an American entrepreneur. The guy managing the podcast would usually record around 30 hours of footage and edit to around 30 minutes. A lot of time goes into making the content engaging, and even if this is community radio, Ciara and Liam's (P3) opinion was that it would need to do this as well.

When there were issues with the robustness of the platform, Martin (P2), Trevor (P2) and Owen (P4) wanted a reliable parallel system that they could switch to when there were problems with it. Trevor (P2), a local volunteer, with sound engineering expertise developed a radio technology set up with Owen (P4) (for transmission and streaming) and pieces of kit that either belonged to volunteers or were left over from an island drama group. In the first year of the radio, Trevor (P2) and Owen (P4) were the only radio volunteers able to operate this system but their support was consistent. The set-up includes computers, cables, a Focusrite scarlett box, free off-the-shelf software called Broadcasting Using This Tool (BUTT) and Itunes to broadcast to an icecast server, and a mixing desk left over from a theatre group, and modem that belongs to Trevor himself (P2). In conversation with the first author and a visiting academic to the island he stated the following: 
Everything is coming out of the computer, all the music, all the sound, and going back in through this [Focusrite scarlett] box into the computer and up. It's quite extraordinary when you think of it. In terms of technology it's fantastic. This is like one hundred quid-this Scarlett box. BUTT (Broadcasting with this tool) is free. And you can run it on any computer. This the community had already, they had a sound desk. They had a drama group. So, the only thing we bought was the microphones. Just invested in those. This computer stuff is mine. That's a modem. I just carry the modem.

When things break down on the island and do not work, other aspects of islandness kick in, the need to make things work. As Trevor (P2) said equating the radio with the popularity of amateur dramatics in Ireland, 'when the lights go up, everything must work.' This is the system that the community radio station currently uses. For now, it is manned by either Trevor (P2) or Owen (P4) and is housed in the local Heritage Centre, making what was once a schoolhouse a living space for social interaction.

Islanding was also evident in the content. Roman Catholic Mass, a service that is well attended by islanders is now regularly broadcast on the radio, enabling those that cannot attend due to travel, ill-health or migration to participate in community activities. Similarly, Gaelic Games, local sports matches, are broadcast around the world to people who can't participate. Whilst broadcasting such services supports the diaspora, it also critically supports local islanders from Public One as well as Public Two. We noted in October 2019:

We arrive and the Church is half full - we sit half-way up. Church filled up fast and I saw people I had never seen before so it's one of the places where people come together as a community on the island. The priest started the ceremony by welcoming everyone and explaining that mass was now live on Island South Community Radio at [frequency] FM and on the world wide web to people listening in around the world. He welcomed people listening in from old folks' homes, hospitals or homes and I felt that the radio was connecting them into this community event. (Fieldnotes, P4)

Radio has also been useful in enabling islanders to hold onto this service which was recently threatened. As the Church has declined across rural Ireland, the number of priests to service rural Churches has declined, with now only two priests servicing the neighbouring mainland peninsula as well as the island. However, as Island South FM transmits radio to the wider area, the priest still regularly travels to the island to say Mass, enabling an important space of community to be maintained (which has been threatened on other islands). Maintaining this social interaction on the island then has been facilitated by the radio. As Bernard (P1) messaged the radio to say the following:

The radio is keeping the Mass on the island and that it's raising the profile of the entire island....

Martin (P2) explains to us that the radio is giving the island power. For example, Martin (P2) explains to us the harbourmaster was invited on the radio to speak about problems with the slipways for travel from the island to the mainland. He declined the invitation, but the slipways were cleared the next day. Sophi (P2) explains that a programme in which islanders or those affiliated with the island talk about their favourite songs is helping islanders get to know each other. Even though she's lived on the island for most of her life, most of her neighbours didn't realise she liked opera 
music. Through the intimacy of radio, the islanders are beginning to get to know each other as individuals, rather than as islanders, and the work of uncovering the collective mask continues.

In this theme we have learned how the particularities of rural islandness particularly related to particularities of community engagement and the multitude of publics play out in the early phase of the community radio project, where public one adopt a watch and wait approach. We also learn how islanding as a verb kicks in as a form of artful integration in which what and who is to hand is integrated into the process.

\section{DISCUSSION}

In our discussion, we will focus on how islandness in the descriptive, socio-cultural and symbolic sense influenced the radio technology platform appropriation process and what factors we will take into consideration in this ongoing project to support participation. We will also consider three elements of rural islandness that can be used as an analytic tool for rural HCI and HCI more broadly. These are (1) separateness, (2) pushing things ahead, and (3) publics and rural pluralities.

\subsection{Separateness}

While the literature sensitizes us to the diverse representations and experiences of rural places, our findings suggest that separateness from the mainland routinely figures in plural representations of islands and all aspects of islanders' lived experiences. Separateness creates material and felt circumstances; higher costs of living, yet tourist income for some; deficits in local services, yet educational attention in a local school; an absence of teenage autonomy yet a desirable quietness and so on. Separateness from the mainland influences the ways relationships are formed, maintained and understood. The distinctive characteristics mentioned by participants have been repeated in HCI research about other rural places, and just as an island is separated from mainland by the ocean, others have mentioned geographical gulfs, such as treacherous gravel roads [5], mountain passes [16], deserts [6] and rainforest waterways [61]. In considering separateness we mean that the actual physical apartness, of the island from mainland, is core to experiences and representations. Separateness always features in islanders' accounts, and perhaps exposes something that is implicit in accounts about other rural areas.

An increased sensitivity to the value of separateness prompts in us a critical reflection on how some HCI and technology development can reproduce the dominant trope of connection; interpersonally, regionally and transnationally [12, 35, 39, 50]. Rural computing, however, challenges assumptions that do not reflect rural residents realities [32]. Rural islandness suggests that 'always on' connections are often unwelcomed by islanders, who enjoy the differences between seasons, and between day and night, and critically the disconnection that an absence of a bridge to the mainland permits. Rural islandness calls on us to reconsider geographic isolation as also offering insulation, and alerts us to the importance of disconnection that has resonances in other rural (and urban) contexts. Various authors have observed that rural inhabitants prefer life where recreational, retail and administrative facilities are not accessible 24-7, e.g., [4], and where time differs from that propagated by 'modern' values embedded in ICT [50]. 'Constrained' use of ICTs is shaped by the weather and communal relationships via intermittent access to shared electricity [5]. Separateness in rural islandness shares some characteristics with resistance to infrastructure dependencies, demonstrated by people who actively choose to live 'off grid' [36,55] or grieved for by people whose livelihood has been made unavailable by mass-mediated forms of networked connectivity [35]. To consider the importance of separateness and geographic isolation as providing insulation could add to Rural HCI researcher's sensitivities when designing from the rural, through attuning to these values. It might also, as Sengers' suggests from her experience on Change Island 
[50], alert us to not just the value but also the cost of modern orientations to time and connectivity, arguing for the importance of a design space which fosters alternatives.

Geographic Isolation is, however, not always insulation, and rural islandness also attunes us to infrastructure dilemmas that bring to the fore the importance of maintenance and repair, just like Persaud finds on Fogo Island and Change Islands (FICI) [44, 45]. Pre-deployment, islanders, located on the edge of contemporary infrastructure networks, asked what type of long-term support would be available to make the technology work if issues arose after the project timeframe. When informed support would remain the same as during the project, they turned silent. Attuning to this silence helped us understand their reticence about the level of support they had received and would receive into the future. When the prototype did not work as intended, 'islandsouthpartner' and volunteers pragmatically decided to use reliable technology instead and to rely on people that could provide trusted ongoing support long into the future, those with technical expertise within the community, or geographically close to it.

Our project was partly focused on the development of a product, a piece of software for community radio, whereas island dwellers were focused on place-making, and how the software might be part of that. While we had hoped these two worlds would align, they did not in the project timeframe. Rural islandness propels us to innovate from what we have and to make things work into the future, through 'repair and care' as artful integration [52]. Artful integration draws attention to aspects of design or cooperative working that are hidden, highlighting them for consideration [58]. Just as islandness is understood by Vannini and Taggart [54:225] as the process of assembling, 'together an island by way of making use of whatever is at hand, solving ongoing concerns as they present themselves', technology in this context becomes part of that assembling, if useful, and disregarded if not.

Islanders did not resist the affordances that the technology intended to provide, but rather, oriented us to the importance of reliability in use, as well as ease of use. While separateness figures in islanders' representations and lived experience, they also repeatedly refer to bridges across the boundary. Our findings show that building bridges, also in the literal sense, is a contested course of action among the island population and opens up questions on how researchers can engage with these conflicts in a context in which collaborating involves a collective mask of solidarity that can hide individual and nuanced differences, and disagreements can be communicated through silence rather than speech.

\section{2 'Pushing Things Ahead': Publics and Strategic Silences as Considerations for Design}

We also learned from rural islandness that silence and non-participation comes along with 'pushing things ahead'. Whilst communal values, collective pride and reciprocal support are strong on Island South, silence around community development helps maintain these values into the future. 'Pushing things ahead' is a trope that could evoke modernity, a linear model of progression with technology as its transmitter [10]. We saw in Section 1 that rural islands are often positioned as backward [41], and in Ireland rural men are derogatively positioned as 'behind' [43], equating rurality with regression. Satchell and Dourish [48] remind us that infrastructure resistance is often associated with a backwardness towards modernity, but can represent other orientations. For example, Luddites, the $18^{\text {th }}$ century textile workers were positioned as resistant to technological progress of modernity, but their resistance was in fact, more to do with labour alienation due to economic changes, than the technology itself [48]. The technology, however, became a symbol of this alienation. On Island South, volunteers feared the technology becoming a symbol of unprofessionalism, perhaps echoing fears of being backward and not technologically competent, that in other contexts rural dwellers are keen to eschew $[42,43]$. Technology in this context becomes an 
important symbol to counter discursive positionings as backward or can be a symbol to perpetuate these positionings. For islanders, reliability of technology was also linked to respect, pride and care of the community. In this way the discursive and symbolic understandings of rurality become important in understanding symbolic understandings of technology and how this might influence appropriation or not, as evident in other rural island contexts [22].

Just as we explore in Section 2.2, where other technology projects have uncovered a tension between rural island communities desire to appear modern, whilst also valuing tradition, there were similar tensions on Island South. In the Islanding radio theme, the mostly male radio volunteers were concerned with the appearance of professionalism. They showed care in considering how people sounded on the radio, and how the radio as the voice of the community came across. This importance of outward facing professionalism was also evident on Jura, where members of Public one would only contribute to a heritage wiki on topics, they were 'expert' in. Thus, on both Island South and Jura, there appears to be a sensitivity to positionings of rural island dwellers as backward rather than progressive. This has ramifications for design. On Island South, public life is performative and piloting technology that breaks down was reputational. This importance of the value of professionalism and reluctance to counter it might also render the de-professionalism (ironically intended to challenge modernity's emphasis on expert knowledge) inherent in both the radio technology platform deployed and Giglitto's [22] jurapedia challenging. We also learned that the initial lack of participation could be related to the importance of maintaining social harmony for reciprocity to continue, which was also evident in other rural island contexts [22, 58].

While the project aimed to support community members' participation and deliberation on issues that matter to them through introduction of a novel platform to support community radio, the technology process highlighted the challenges of speaking freely in the micro-society of the island, where open debate and confrontation is resisted, whilst grudges can linger. When Island South Community Radio is on-air, the front stage or the collective mask is evident as volunteers broadcast to audiences from the island, the mainland or the diaspora. In the backstage, however, different publics consider how the radio might support their needs or amplify one Public's interests over another. Yet these concerns remain publicly unarticulated to the wider public of the island.

A radio station designed to give people a say, when introduced in a rural island context, needs to deal with these 'strategic silences' [58]. We suggest that the designer's role consists in both the identification of these silences and in exploring what socio-technical infrastructures can allow people to voice concerns and ideas without compromising social relationships. In this type of rural context, we find responding to controversies between different publics and audiences, the construction of agonistic public spaces cannot only be based on 'activities full of passion, imagination and engagement' [7:48] but must also contemplate the possibility of managing and understanding silence and its causes. As researchers and designers, we are not separate to these controversies but rather become part of them through being positioned as public Four on the island.

We suggest that the first step to managing silences is to recognize and listen to them and understand whether or not they relate to exclusions. In the rural island context, as in other contexts, there are norms of speaking that if violated can have real world consequences. We initially attempted traditional participatory design approaches such as workshops, which were not well attended, and particularly poorly attended by Public One. Our role as outsiders to the community, however, can be useful in that people sometimes find it easier to air their grievances to us, than to each other, suggesting that the designer's role can be in articulating what remains unsaid. This is similar to what Brereton and colleagues $[8,9]$ find on Groote Eylandt, in which the indigenous community rejects HCI workshops, favouring engagement based on familiarity, mutuality and integration of design into existing everyday practices. Rural islandness teaches us that to be part of its placemaking is to commit to place and to artfully integrate into its ways and values or be cast aside 
as irrelevant. This has implications for HCI's engagement in rural island contexts, and perhaps in other rural contexts too.

\subsection{Publics and Rural Pluralities on the Island}

The controversy of 'pushing things ahead' also brings to the fore the different perspectives of Gill's [23] four island Publics, with local islanders of Public One more commonly staying silent or 'sitting on their tension' preventing them from openly voicing concerns about the future of the island. These silences rendered unsaid concerns about which representation of the rural should be prioritized in future development and which publics have a stake. For example, representations of the island as a summer-playground attracts tourism. This has material consequences, when houses are not available to rent for year-round dwellers and ferry timetables are pivoted around Public Three and Four interests over local year-round needs. Increased tourist traffic and busyness then threatens the beauty of the rural landscape that Public One and Two enjoy, through changing the elements of the rural that first attracted Public Three and Four. This is a process called creative destruction, which Mitchell [40] suggests results in the destruction of the rural idyll as the landscape becomes commodified for leisure rather than a site of primary production. Just as in Orkney, the idea of 'haunted islands' [58] also looms close to Island South. While these processes of creative destruction are not unique to islands, nor indeed to rural places (e.g., Barcelona and other European cities have similar tensions), the strategic silences around them is pronounced in the rural island context creating challenges in addressing this cycle of destruction and transformation. Finding a way for community technologies to support a version of rural pluralities that enhances rather than destroys particular ruralities is a remaining challenge for our future work, and an important challenge for rural computing in general to consider.

Whilst technology is often about imagining potential futures, Brynjarsdóttir and Sengers [10] remind us of the unintended consequences of technology in other rural contexts, where mechanization of fishing led to under employment, particularly for women. With this legacy, it is not surprising that Island South islanders are suspicious about outsiders introducing a new technology. Staging and shaping encounters that can make visible these tensions around technology are important in rural contexts, as is an awareness of the sometimes-unintentional privileging of one public over another through technology deployment and design processes.

We find on Island South that we are solely working with Public Two, who generally speak more freely and are supportive of change. This is similar in HCI research on Jura, where Public Two was deemed easier to engage due to synergies with urban values and interests [22]. We find on Island South that Public One will wait-and-watch to see which representation of the island will be most supported by radio technology, and whether the radio aligns with their values or not. Whilst our previous research [49] suggested that finding a way for Public Three to participate in community through community radio technologies is important, this article further suggests that finding ways to balance participation of the publics and to enable Public One to speak is a greater challenge for us as designers, but one we must consider. Supporting local culture to survive, and lost social interactions to be reignited, are important considerations for rural HCI, as Brynjarsdóttir and Sengers also find [10]. We saw that through islanding the radio, the community radio has enabled one important social interaction for the island (weekly Mass) to be maintained. Islanding radio has created another space of social interaction through the radio studio in a Heritage Centre, turning a space designed to 'preserve' a culture under threat, into a living space of culture and community. As rural life is increasingly threatened by urbanization, globalization, and economic forces that lead to youth out-migration and rural gentrification, we find that rural islandness attunes us to the inter-public dynamics of place that can be a contribution for rural HCI more broadly through emphasizing that technology deployment takes place within a web of inter-community dynamics. 
As rural computing engages with multiple ruralities [30], we hope that our exploration of rural islandness can attune others to the usefulness of considering rural publics and in particular of how to engage with Public One.

Publicness of the island also heightens located accountabilities and provides a reverse gaze to us as researchers. While we initially thought our job was to support islanders to overcome their reluctance in engagement, we realised that $\mathrm{HCI}$ design strategies that expect people to embrace the messiness of the design process with no guarantee of pay-off is problematic. As we see in the sub-theme 'good for whom', the watch and wait approach to see whether the radio project would be of benefit is a logical response of island dwellers, with deep-rooted community relationships and connections to maintain. Not surprisingly island dwellers were more concerned about maintaining relationships than with the imagined practices of the radio. If $\mathrm{HCI}$ and rural computing is to take rural islandness sensibilities seriously, we must form collaborations that are rooted in place-making and mutuality as central to the research and design process. While in this instance, piloting of the prototype was a failure, Watts [57] suggests that rural islands such as Orkney can be rich spaces for prototype development, as long as such development is based on place-making and mutuality. In Orkney this, 'requires those who visit with their prototypes to understand that in testing them, in getting them working, and learning from the islands, they become participants in making an Orkney future as well as their own; collaboration comes with obligations that go both ways' [58:22]. This echoes Brereton and colleagues [8,9] and Dix and colleagues [13, 18, 19, 51] approaches on Groote Eylandt and Tiree respectively. For our project, this meant a reconfiguration of the process, where the prototype we had initially planned to develop was not used. Through non-use, however, we continue to learn about community engagement in this type of context, and what went wrong becomes generative in learning what could make things right.

\section{CONCLUSION}

Whilst we have focused on the separateness of the islands, islands are by their nature places of rootedness but also of routes [1] - to the mainland, to other islands via the sea, and now through the spanning capacity of the community radio technology to islanders and those affiliated with the island that live all over the world. The radio is supporting rootedness through keeping vital services such as the Mass on the island, but also has potential to create dialogue between islanders from all Gill's publics, if a space can be found to nurture Public One who is more fearful of engagement. Islandness makes public the piloting of technology and creates a heightened located accountability for those involved in the process when competing demands of regulators and of island publics as audiences are placed on volunteers. As a result, islanding, as a form of artful integration kicks in, which values maintenance and repair and local knowledge and support systems. We hope to contribute to rural $\mathrm{HCI}$ by indicating the values that rural islandness teach us about considering separation, including geographic isolation as both isolation and insulation as a consideration for design; strategic silences as part of the design process and of the importance of inter-public relations in rural contexts. Through rural islandness we learn about the types of research engagement that might sustain HCI research, and also mutually of rural place. Our research also indicates that in such contexts, designers need to hold simultaneous views. First seeing the importance of the social glue and the symbolic importance of a community identity that is separate; while secondly, mutually, recognizing the plurality within it.

A tension throughout this article is whether to design 'for' or 'from' the rural, just as Hardy and colleagues [32] debate in recent work and others [4] raised in work from the Global South. Whilst we are advocates of designing 'from' the rural, our research indicates that we must design 'from' the multiple rural perspectives that co-exist in rural places, rather than indicating design from the rural, we suggest a need to design from positions of rural pluralities, considering the interweaved 
connections between the various rural publics engaged in community. Whilst the radio technology designed for use in this community was designed elsewhere, we had hoped to finetune its design 'from' the rural island context of use. However, the values of the technology and its readiness for use did not match the expectations and values of the rural island dwellers. Bringing together our experience with the literature from rural $\mathrm{HCI}$ and on rural islands, we suggest that investing in place-making is vital for design from small rural contexts and that the model of the Tiree Tech Wave where design ideas stem from a collaboration between designers and islanders from the rural context is the way forward [19]. Creating ways to forge these real world, useful exchanges is important way forward for rural $\mathrm{HCI}$ and one that we hope donors will support.

\section{ACKNOWLEDGMENTS}

We would like to thank the people of Island South for participating in this research. We would also like to thank three anonymous TOCHI reviewers for their careful feedback and generous suggestions on our first and second drafts of this article. We are also grateful to Fleur Ward from the University of the Highlands and Islands for her support in this research.

\section{REFERENCES}

[1] Godfrey Baldacchino. 2004. The coming of age of island studies. Tijdschrift voor Economische en Sociale Geografie 95 , 3 (2004), 272-283.

[2] Godfrey Baldacchino. 2005. The contribution of 'social capital' to economic growth: Lessons from island jurisdictions. The Round Table 94, 378 (2005) 31-46.

[3] Godfrey Baldacchino. 2007. Islands as novelty sites. Geographical Review 97, 2 (2007), 167-174.

[4] Nicola J. Bidwell and David Browning. 2010. Pursuing genius loci: Interaction design and natural places. Personal \& Ubiquitous Computing 14, 1 (2010) 15-30.

[5] Nicola J. Bidwell, Masbulele Siya, Gary Marsden, William D. Tucker, M. Tschemese, N. Gaven, S. Ntlangano, Simon Robinson, and Kristen Ali Eglinton. 2013. Walking and the social life of solar charging in rural Africa. ACM Transactions on Computer-Human Interaction 20, 4 (2013), 1-33.

[6] Nicola J. Bidwell and Heike Winschiers-Theophilus. 2012. Extending connections between land and people digitally. In Heritage and Social Media: Understanding Heritage in a Participatory Culture. Elisa Giaccardi (Ed.), Routledge.

[7] Erling Björgvinsson, Pelle Ehn, and Per-Anders Hillgren. 2010. Participatory design and 'democratizing innovation'. In Proceedings of the 11th Biennial Participatory Design Conference. 41-50. DOI : https://doi.org/10.1145/1900441. 1900448

[8] Margot Brereton, Paul Roe, Thomas Amagula, Serena Bara, Judy Lalara, and Anita Hong Lee. 2013. Growing existing aboriginal designs to guide a cross-cultural design project. In Proceedings of the IFIP Conference on Human Computer Interaction. 323-330.

[9] Margot Brereton, Paul Roe, Ronald Schroeter, and Anita Lee Hong. 2014. Beyond ethnography: Engagement and reciprocity as foundations for design research out here. In Proceedings of the SIGCHI Conference on Human Factors in Computing Systems. 1183-1186.

[10] Hrönn Brynjarsdóttir and Phoebe Sengers. 2010. Ubicomp from the edge of the North Atlantic: Lessons from fishing villages in Iceland and Newfoundland. In Proceedings of the 11th International Conference on Ubiquitous Computing.

[11] Vanessa Burholt and Kieran Walsh. 2013. Imagery and imaginary of islander identity: Older people and migration in Irish small-island communities. fournal of Rural Studies 31, 1-12.

[12] Marta E. Cecchinato, Anna L. Cox, and Jon Bird. 2017. Always on(line)? User experience of smartwatches and their role within multi-device ecologies. In Proceedings of the 2017 CHI Conference Extended Abstracts on Human Factors in Computing Systems. 3357-3568.

[13] A. Chamberlain, A. Malizia, and A. J. Dix. 2013. Engaging in island life: Big data, micro data, domestic analysis and smart islands. In Proceedings of the ACM Conference on Pervasive and Ubiquitous Computing Adjunct Publication.

[14] Roberto Cibin, Maurizio Teli, and Sarah Robinson. 2019. Institutioning and community radio. A comparative perspective. In Proceedings of the 9th International Conference on Communities \& Technologies-Transforming Communities. 143-154.

[15] Anthony P. Cohen. 1987. Whalsay: Symbol, Segment and Boundary in a Shetland Island Community. Manchester.

[16] Lamichhane Dev Raj, Janet C. Read, and Dan Fitton. 2018. Beneath the Himalayas-Exploring design for cultural evenness with Nepalese children. In Proceedings of the 32nd International BCS Human Computer Interaction Conference. 1-5. 
[17] Alan Dix. 2014. Open Data Islands and Communities. Tiree. Retrieved from https://tireetechwave.org/wp-content/ uploads/2014/07/Open-Data-Islands-and-Communities-v3b.pdf.

[18] Alan Dix. 2016. The Leaves Are Golden-Putting the Periphery at the Centre of Information Design. Retrieved from https://www.alandix.com/academic/talks/HCI2016-the-leaves-are-golden/.

[19] Alan Dix, Alan Chamberlain, and Duck Roulette. 2020. Tiree Tech Wave. Retrieved 2020 from https://tireetechwave. org/.

[20] Alan Dix, Alessio Malizia, Tommaso Turchi, Steve Gill, Gareth Loudon, Richard Morris, Alan Chamberlain, and Andrea Bellucci. 2016. Rich digital collaborations in a small rural community. In Proceedings of the Collaboration Meets Interactive Space. Springer, Cham, 463-483.

[21] Diarmuid Ferriter. 2018. On the Edge: Ireland's Off-Shore Island: A Modern History. Profile Books, London.

[22] Danillo Giglitto. 2017. Community empowerment through the management of intangible cultural heritage in the Isle of Jura, Scotland. Imperial fournal of Interdisciplinary Research 3, 5 (2017), 567-578.

[23] Peter Gill. 1984. Island psyche: Fieldnotes from an Irish island. The Irish fournal of Applied Psychology 15, 2-3 (1984), 276-287.

[24] Peter Gill. 2019. On the sustainability of small offshore islands. Keynote Lecture. UCC Think-In about Sustainability of the West Cork Islands.

[25] J. Gillis. 2004. Taking history offshore: Atlantic islands in European minds. In Islands in History and Representation. Rod Edmond and Vanessa Smith (Eds.). Routledge, London, 19-31.

[26] Keith Halfacree. 1996. Out of place in the country: Travellers and the 'rural idyll'. Antipode 28, 1 (1996), 42-72.

[27] Keith Halfacree. 2006. Rural space: constructing a three-fold architecture. In Handbook of Rural Studies. SAGE Publications, London, 44-62.

[28] Donna J. Haraway. 2016. Staying with the Trouble: Making Kin in the Cthulucene. Duke University Press.

[29] J. Hardy, S. Wyche, and T. Veinot. 2019. Rural HCI research: Definitions, distinctions, methods, and opportunities. In Proceedings of the ACM on Human-Computer Interaction. 1-33.

[30] Jean Hardy, Dharma Dailey, Susan Wyche, and Norman Makoto Su. 2018. Rural computing: Beyond access and infrastructure. In Proceedings of the Companion of the 2018 ACM Conference on Computer Supported Cooperative Work and Social Computing. 463-470.

[31] Jean Hardy and Syliva Lindtner. 2017. Constructing a desiring user: Discourse, rurality, and design in location based social networks. In Proceedings of the 2017 ACM Conference on Computer Supported Cooperative Work and Social Computing. 13-25.

[32] Jean Hardy, Chanda Phelan, Morgan Vigil-Hayes, Normal Makato Su, Susan Wyche, and Phoebe Sengers. 2019. Designing from the rural. Interactions 26, 4 (2019), 37-41.

[33] Jean Hardy and Stefani Vargas. 2019. Participatory design and the future of rural LGBTQ communities. In Proceedings of the Companion Publication of the 2019 on Designing Interactive Systems Conference. 195-199.

[34] Pete Hay. 2006. A phenomenology of islands. Island Studies fournal 1, 1 (2006), 19-42.

[35] Pepita Hesselberth. 2018. Discourses on disconnectivity and the right to disconnect. New Media \& Society 20, 5 (2018), 1994-2010.

[36] S. Mainwaring, M. Chang, and K. Anderson. 2004. Infrastructure and its discontents: Implications for ubicomp. In Proceedings of the Ubicomp. 418-432.

[37] Andrew Mauder, Gary Marsden, and Willian David Tucker. 2006. Evaluating the relevance of the "real access" criteria as a framework for rural HCI research. In Proceedings of the CHI-SA 2006. 75-79.

[38] Laura Maye, Sarah Robinson, Nadia Pantidi, Liana Ganea, Oona Ganea, Conor Linehan, and John McCarthy. 2020. Considerations for implementing technology to support community radio in rural communities. In Proceedings of the 2020 CHI Conference on Human Factors in Computing Systems. 1-13. DOI : https://doi.org/10.1145/3313831.3376580

[39] Melissa Mazmanian and Ingrid Erickson. 2014. The product of availability: understandings the economic underpinnings of constant connectivity. In Proceedings of SIGCHI Conference on Human Factors in Computing Systems. 763-772.

[40] Clare J. A. Mitchell. 1998. Entrepreneurialism, commodification and creative destruction: A model of post-modern community development. fournal of Rural Studies 14, 4 (1998), 273-286.

[41] S. Moncada, M. Camilleri, S. Formosa, and R. Galea. 2010. From incremental to comprehensive: Towards islandfriendly European union policymaking. Island Studies fournal 5, 1 (2010), 61-88.

[42] Catríona Ní. Laoire. 2002. Young farmers, masculinities and change in rural Ireland. Irish Geography 35, 1 (2002), $16-27$.

[43] Catríona Ní. Laoire. 2005. "You're not a man at all!" Masculinity, responsibility and staying on the land in contemporary Ireland. Irish fournal of Sociology 14, 2 (2005), 16-27.

[44] Donny Harry Persaud. 2018. Behind Breakdown: The Case of the MV Veteran. Memorial University of Newfoundland.

[45] Donny Harry Persaud, Josh Lepawsky, and Max Liboiron. 2019. Viscous objects. The uneven resistances of repair. Techniques and Culture 72, 1-23. 
[46] Sarah Robinson, Nicola J. Bidwell, Laura Maye, Nadia Pantidi, and Conor Linehan. 2020. Participation through substituting and refusing. In Proceedings of the 16th Participatory Design Conference 2020: Exploratory Papers.

[47] Nicolette Rousseau. 1995. What is rurality? Occassional Paper, Royal College of General Practitioners 71, 71 (1995), 1-4.

[48] Christine Satchell and Paul Dourish. 2009. Beyond the user: Use and non-use in HCI. In Proceedings of the 21st Annual Conference of the Australian Computer-Human Interaction Special Interest Group. 9-16.

[49] B. Saunders, J. Kitzinger, and C. Kitzinger. 2015. Anonymising interview data: Challenges and compromise in practice. Qualitative Research 15, 5 (2015), 616-632.

[50] Phoebe Sengers. 2011. What I learned on change islands: Reflections on IT and pace of life. Interactions 18, 2 (2011), 40-48. DOI : https://doi.org/10.1145/1925820.1925830

[51] Will Simm, Maria Angela Ferrario, Adrian Friday, Peter Newman, Stephen Forshaw, Mike Hazas, and Alan. Dix. 2015. Tiree energy pulse: Exploring renewable energy forecasts on the edge of the grid. In Proceedings of the 33rd Annual ACM Conference on Human Factors in Computing Systems. 1965-1974.

[52] Lucy Suchman. 2002. Located accountabilities in technology production. Scandinavian fournal of Information Systems 14, 2 (2002), 91-105.

[53] Philip Vannini. 2011. Constellations of ferry (im)mobility: Islandness as the performance and politics of insulation and isolation. Cultural Geographies 18, 2 (2011), 249-271.

[54] Philip Vannini and Jonathon Taggart. 2013. Doing islandness: A non-representational approach to an island's sense of place. Cultural Geographies 20, 2 (2013), 225-242.

[55] Philip Vannini and Jonathon Taggart. 2013. Do-it-yourself or do-it-with? The regenerative life skills of off-grid home builders. Cultural Geographies 21, 2 (2013), 267-285.

[56] Fleur Ward. forthcoming. Information and Communication Technology's Role in the Governance of Sub National Island Jurisdications (SNIfs): Successes, Failures and Lessons from Scotland's Island Councils (Provisional Title). University of the Highlands and Islands, Orkney.

[57] Laura Watts. 2014. Liminal Futures: Poems for islands on the edge. In Subversion, Conversion, Development: CrossCultural Knowledge Exchange and the Politics of Design, James Leach and Lee Wilson (Eds.). MIT Press, Cambridge, MA, 19-38.

[58] Laura Watts. 2018. Energy at the End of the World: An Orkney Islands Saga. MIT Press.

[59] H. Winschiers-Theophilus, S. Chivuno-Kuria, G. K. Kapuire, N. J. Bidwell, and E. Blake. 2010. Being participated: A community approach. In Proceedings of the 11th Biennial Participatory Design Conference. 1-10.

[60] Michael Woods. 2010. Rural. Taylor and Francis Group, London.

[61] Tariq Zaman and Heike Winschiers-Theophilus. 2015. Penan's Oroo' short message signs: Co-design of a digital jungle sign language application. In Proceedings of the IFIP Conference on Human-Computer Interaction. 489-504.

Received May 2020; revised October 2020; accepted December 2020 